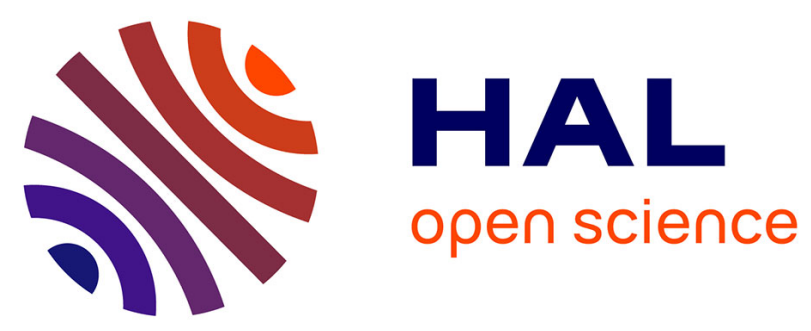

\title{
Experimental validation of a hybrid emergency network with low and medium voltage Li-Ion batteries for more electrical aircraft
}

Fabien Lacressonnière, Eric Bru, Guillaume Fontes, Xavier Roboam

\section{- To cite this version:}

Fabien Lacressonnière, Eric Bru, Guillaume Fontes, Xavier Roboam. Experimental validation of a hybrid emergency network with low and medium voltage Li-Ion batteries for more electrical aircraft. 2013 15th European Conference on Power Electronics and Applications (EPE), Sep 2013, Lille, France. 10.1109/EPE.2013.6634664 . hal-02867941

\section{HAL Id: hal-02867941 https://hal.science/hal-02867941}

Submitted on 15 Jul 2021

HAL is a multi-disciplinary open access archive for the deposit and dissemination of scientific research documents, whether they are published or not. The documents may come from teaching and research institutions in France or abroad, or from public or private research centers.
L'archive ouverte pluridisciplinaire HAL, est destinée au dépôt et à la diffusion de documents scientifiques de niveau recherche, publiés ou non, émanant des établissements d'enseignement et de recherche français ou étrangers, des laboratoires publics ou privés. 


\title{
Experimental validation of a hybrid emergency network with low and medium voltage Li-Ion batteries for more electrical aircraft
}

\author{
F. Lacressonnière, E. Bru, G. Fontes, X. Roboam \\ Université de Toulouse; LAPLACE (Laboratoire Plasma et Conversion d'Energie) UMR \\ CNRS-INPT-UPS ; ENSEEIHT \\ 2 rue Charles Camichel, BP 7122, F-31071, Toulouse, France \\ Tel.: +33 (0)5 34322403 Fax: +33 (0)5 61638875 \\ E-Mail: fabien.lacressonniere@laplace.univ-tlse.fr \\ URL: http://www.laplace.univ-tlse.fr/
}

\section{Acknowledgements}

This study has been involved in the framework of the ISS (Innovative Solution for Systems) national project for which the authors thank the DGAC (Direction Générale de l'Aviation Civile) and Airbus operation SAS for support and funding. Authors also like to thank SAFT for scientific cooperation.

\section{Keywords}

« Aerospace», « Airplane», « Hybrid power integration», « Energy storage».

\begin{abstract}
This paper deals with a hybrid electrical network for an aircraft in emergency operation. The principle of this network is to hybridize, through a bidirectional DC/DC converter, a high speed Ram Air Turbine (RAT) with an electrochemical Lithium Ion accumulator. A design study of DC/DC power converters, according to the voltage of the accumulator, is presented. The results of this study have shown that utilization of a medium-voltage battery can be a good mass / efficiency trade off of the overall system. Some experiments on a lab test bench have allowed validating the principle of the hybridization and several energy management strategies have been tested with low and medium voltage lithium ion batteries.
\end{abstract}

\section{Introduction}

To limit the impact of air traffic on environment, aircraft industry has to reduce fuel consumption and CO2 emissions [1]. The "more electric aircraft" can help reaching these environmental and technological challenges [2,3]. Some conventional equipments, which depend on hydraulic or pneumatic power, are more and more substituted by electrical systems such as flight control actuators [2], de/anti icing or air conditioning systems [4]. Hence, the demand for embedded electrical power has significantly increased $[2,5,6,7,8]$. Increasing electricity power in modern aircrafts also allows changing actual emergency appliances, using almost exclusively electrical energy in the case of total power loss during engines failure. During this operation, energy generation is often ensured by a high speed wind turbine (RAT) that unfolds in case of engine failure. This turbine is currently designed to provide the maximum power that aircraft may require during emergency mission. A previous study has demonstrated that significant reduction in weight and volume of the whole emergency system can be obtained by hybridizing the turbine with a storage device $[7,8]$ : about $25 \%$ of mass reduction could be expected on the system.

This paper presents an emergency sub network in which the RAT is hybridized with a Li-Ion accumulator. Firstly, the authors present the principle of the hybridization. An experimental validation of the hybridization concept with a low voltage lithium ion battery $(28 \mathrm{~V}$ being the classical voltage standard for batteries) on a test bench has been done. A design study to estimate the best connection voltage of the accumulators has been carried out [8]. The results of this study have showed that an optimum for the connection voltage appears to be between $200 \mathrm{~V}$ and $300 \mathrm{~V}$ in terms of power 
electronic structure and battery trade off. Hence, another experimental validation has been done on the test bench with a $216 \mathrm{~V} \mathrm{Li-Ion} \mathrm{accumulator} \mathrm{and} \mathrm{the} \mathrm{experimental} \mathrm{results} \mathrm{will} \mathrm{be} \mathrm{detailed} \mathrm{in} \mathrm{this} \mathrm{paper.}$

\section{The principle of the hybridization and control strategies}

During the TEFO (Total Engine Failure Operation) of the aircraft, a RAT (Fig.1) is deployed (manually or automatically) and this one ensures the energy generation to power the essential network with flight control actuators, avionic loads, essential lighting and de-icing. A RAT is composed of a wind turbine with two blades. The turbine is coupled to a synchronous generator (SG) through a speed multiplier. A diode bridge is connected between the generator and the DC bus capacitance to rectify the voltage.

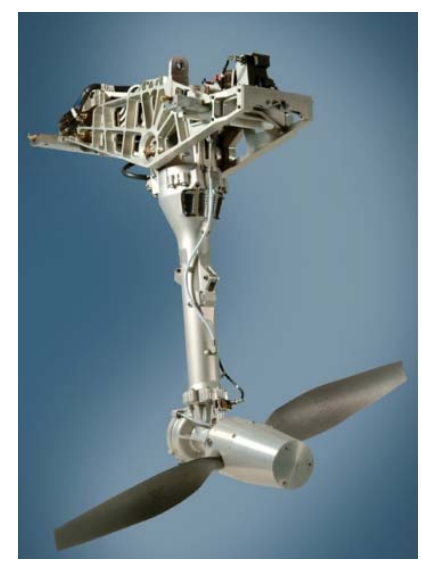

Fig.1 : The Hamilton Sundtrands A380 RAT picture

Several studies $[7,8]$ have showed that the hybridization of the RAT with storage technologies (supercapacitors or batteries) allows increasing system performance and decreasing the RAT sizing (weight, volume). The hybridization is based on the principle of power sharing where the average power is supplied by the main power source (i.e the RAT) while transient load is fed by the storage device.

Two hybridization strategies are possible:

- the first one, with storage (here the battery) in "current mode" (Fig. 2), operates the RAT as a constant bus voltage source and the storage bank as a transient current source $\left(\mathrm{I}_{\text {source }}\right)$. The reference current for storage is the high frequency part of the load current $\left(I_{\text {load }} H F\right)$. Due to the high pass filtering effect, the storage sub system only provides the intermittent power, especially due to flight control surface motion, with harmonics beyond the filter cut off frequency. The RAT only delivers the average power and low frequency harmonics.

- in the second strategy with battery in bus "voltage mode" (Fig. 2), sources nature is swapped: the RAT is used as a controlled current source, while the storage system is responsible for controlling the DC bus voltage. In this case, the reference current of the RAT contains the Low Pass Filtered (LPF) load current $\left(I_{\text {load }} L F\right)$. The average power consumption of the load and system losses are supplied by the RAT while intermittent powers are naturally fed by the lithium ion battery by balancing source and load power to maintain the bus voltage. As for classical wind turbine systems, this strategy allows MPPT (Maximum Power Point Tracking) of the RAT [7].

On the figure 2, the DC/DC power converter allows interfacing a High Voltage Direct Current (HVDC) bus with the Li-Ion battery which respectively controls the High Frequency load current (left part) or the HVDC bus voltage (right part). 


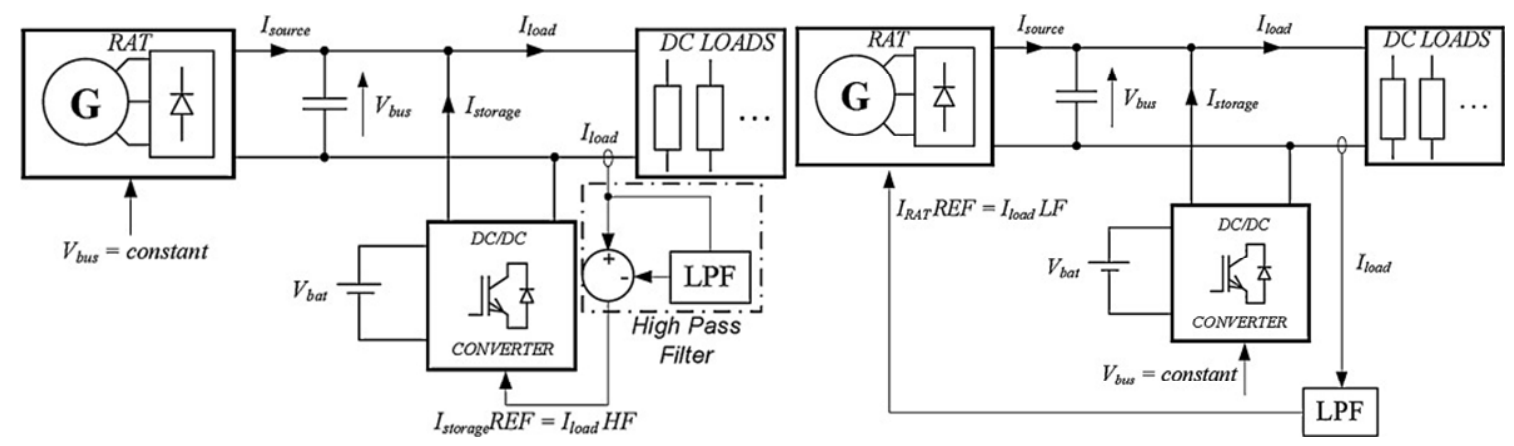

Fig. 2: Schemes of hybridization control structures with battery in current (left) and voltage (right) modes

\section{Experiments on a hybrid emergency network with a $28 \mathrm{~V}$ Li-Ion battery}

The LAPLACE laboratory is equipped with an experimental test bench which reproduces a simplified HVDC electrical network emulating a future more electrical aircraft (Fig.3). The system is mainly composed of three EPC's (electrical power centers). Each of them is able to interconnect up to six DC sources and loads. Power bidirectional exchanges between each EPC are possible with DCPFC's (Direct Current Power Flow Controllers). DCPFCs are static converters, which can be controlled in voltage mode or current mode. As the LAPLACE laboratory is not equipped with an actual RAT, this latter has been physically emulated by DC generators constituted of three phase autotransformers with diode rectifiers. The lithium ion battery is connected to the storage bank.
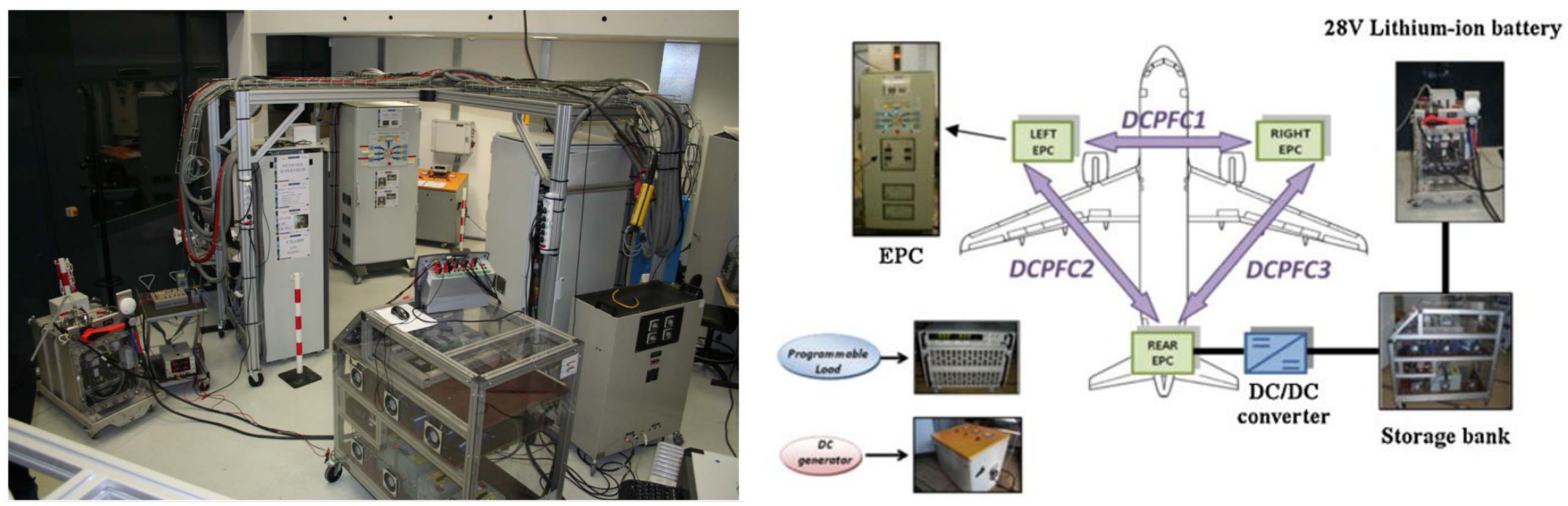

Fig. 3: The experimental test bench and the structure of the HVDC electrical network

Control and energy management strategies have been programmed via Matlab/Simulink: the whole system (DCPFC, DC/DC converter, contactors placed in EPC's) is managed by the DSPACE supervisor and the ControlDesk software. According to the selected strategies, the DSPACE manages the experimental bench and emulates the emergency mission profile (Fig.4) thanks to programmable power loads. Several mission profiles, corresponding with typical flight cycles in case of TEFO (Total Engine Failure Operation), have been applied for the hybridization of the RAT with the lithium ion battery. A main generator failure has been implemented in the experimental test bench. The configuration of the experimental test bench is represented in Fig. 5. The voltage level of the HVDC bus is chosen at $270 \mathrm{~V}$. This HVDC bus voltage allows complying with the dynamic loads connected at the rear EPC which emulate the profile of the emergency mission. 


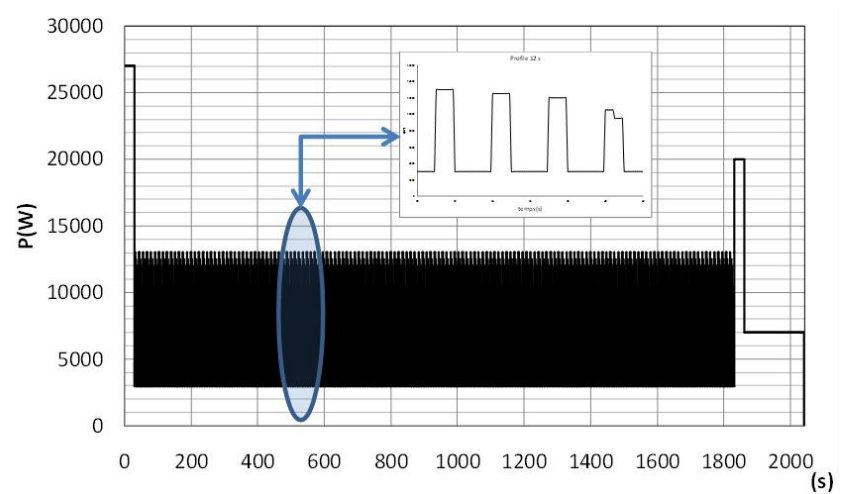

Fig. 4: The experimental emergency power load profile

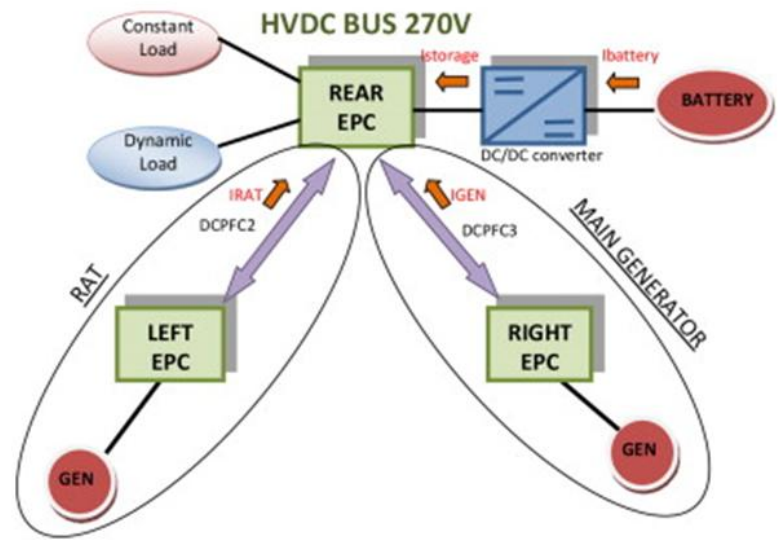

Fig. 5: Configuration of the test bench with the 28V Li-ion battery

In Fig. 6, experimental results obtained on the lab test bench are presented, with the system being configured as follows:

- Lithium ion battery with nominal voltage of $28 \mathrm{~V}$; capacity : $60 \mathrm{Ah}$.

- HVDC bus voltage is controlled to 270V.

- The cut off frequency of the Low Pass Filter is set at $10 \mathrm{mHz}$.

- The level of power load profile has been reduced.

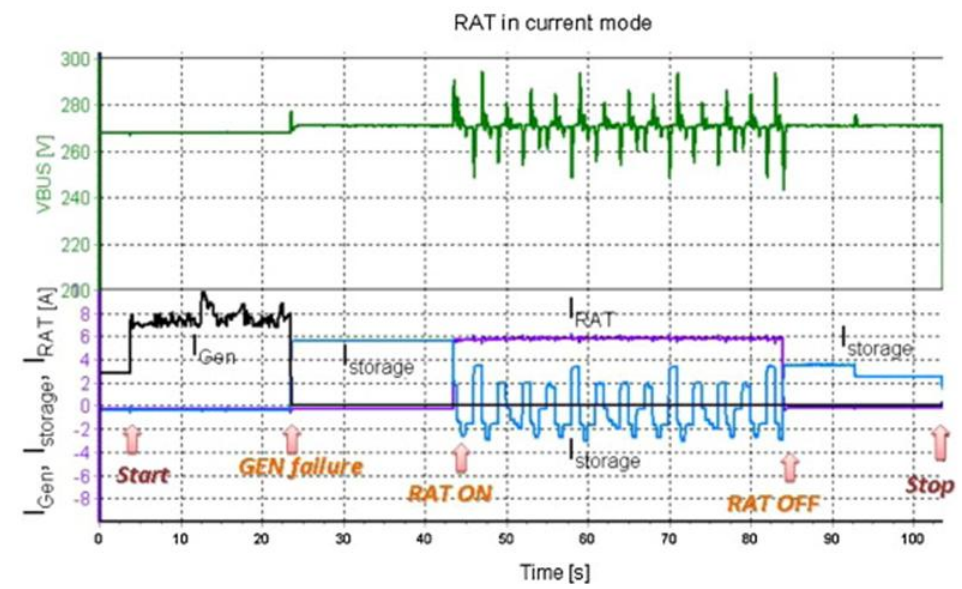

Fig. 6: Experimental results with a 28V Li-Ion accumulator (RAT in current Mode)

During this hybridization mission, the RAT only provides the low frequency part of load currents (the current of the RAT is nearly constant). The DC/DC converter (Fig.5), which is connected to the battery, provides the high frequency harmonics. However, the frequency bandwidth of the DC/DC converter, placed in our lab test bench, is too low to provide the totality of high frequency components. Then, the highest frequencies, which are not supported by the DC/DC converter, are 
provided by the HVDC bus capacitor which slightly impacts the quality of the bus voltage. A DC/DC converter with a higher bandwidth would lead to better control the HVDC bus voltage during the hybridization.

These experimental results have shown the feasibility of the hybridization principle with a RAT and a lithium ion battery. Two significant advantages lead to choose the RAT in current mode control with storage in HVDC bus regulation:

1. This strategy offers the possibility to implement a Maximum Power Point Tracking algorithm to exploit RAT in optimal conditions as for classical wind turbines [7].

2. The storage device is continuously in voltage mode from the TEFO state, which avoids algorithm switching between voltage and current mode, whereas these algorithm switching are necessary when the RAT controls the HVDC voltage.

\section{Design study and optimization of the battery voltage}

A recent study has been carried out to estimate the best connection voltage of the accumulator in terms of mass and efficiency for the embedded power electronics together with the battery bank [8]. A 540V HVDC (High Voltage Direct Current) bus feds the high power essential loads such as flight controls surfaces (FC), de ice or emergency braking for a maximum consumption estimated to $27 \mathrm{~kW}$. A power electronic can connect the HVDC bus to a 28V LVDC (Low Voltage Direct Current) bus supplying the "avionic bus" feeding flight computers and other loads that can be seen as a constant power load of $4 \mathrm{~kW}$. The characteristics of components used in the power converters, in order to respect the input data specifications, are calculated with the design strategy implemented in spreadsheets [8]. The topologies of the power converters and the design strategy are presented in Fig. 7.

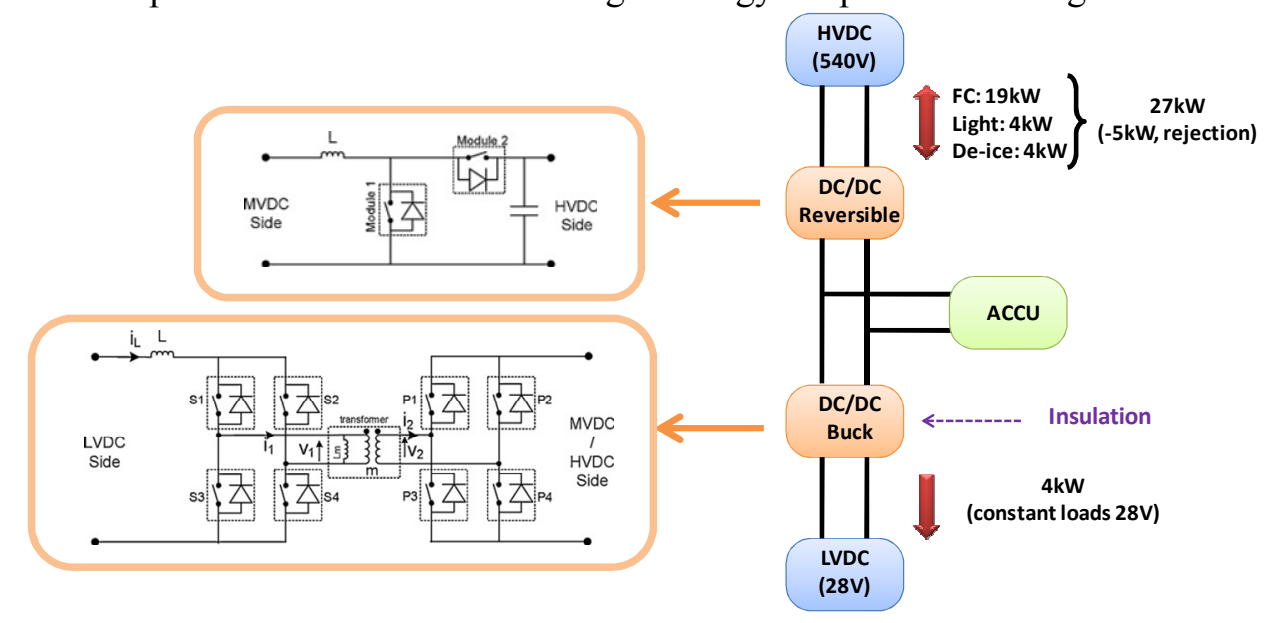

Fig. 7: Topologies of power converters and the design strategy

\section{Structure with Low Voltage Direct Current accumulator}

For this network configuration (Fig.8), a LVDC (28V)/HVDC (540V) isolated buck boost power converter is used. The design strategy [8] has allowed obtaining a mass of $34 \mathrm{~kg}$ and $80 \%$ for efficiency. The mass of the $28 \mathrm{~V}$ battery is estimated at $48 \mathrm{~kg}$. 


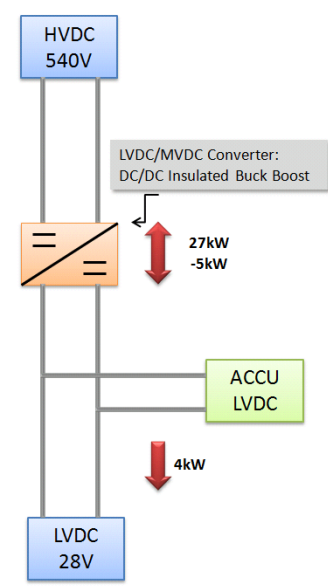

Fig. 8: The network configuration with LVDC accumulator

\section{Structure with medium Voltage Direct Current accumulator}

Both insulated and non insulated converters are needed for this structure (Fig. 9). Increasing the MVDC voltage is better for the efficiency of the non insulated topology that ensures the MVDC/HVDC conversion (reduced power losses in power switches). For the insulated buck converter, the turns ratio of the transformer has a major impact and we notice that losses in the switches and in the transformer are the most significant [8].

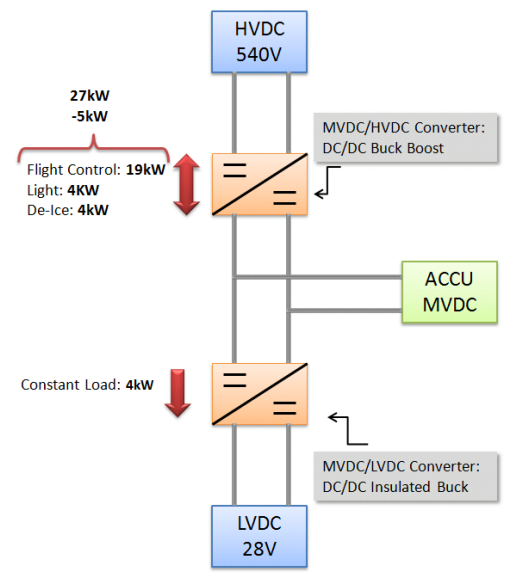

Fig. 9: The network configuration with MVDC accumulator

\section{Mass of the system}

The Fig. 10 presents the system mass versus the connection voltage. The low and medium Li-Ion voltage battery is indicated. The optimum sizing for connection voltage appears to be between $200 \mathrm{~V}$ and $300 \mathrm{~V}$. 


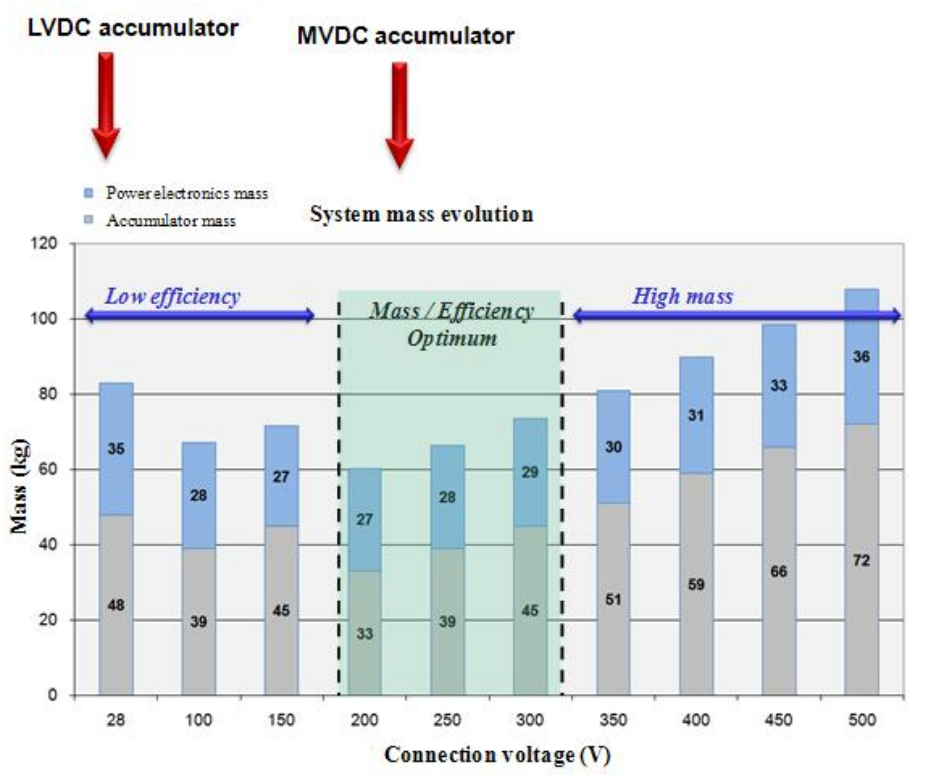

Fig. 10: Mass of overall system

The results of this study have been tested by experiments on the lab test bench with a MVDC lithium ion battery.

\section{Experiments on a hybrid emergency network with a $216 \mathrm{~V} \mathrm{Li}$-Ion battery}

Hence, the experimental validation of the hybrid emergency system, with a $216 \mathrm{~V}$ Li-ion battery, has been planned on the same test bench. The voltage level of the HVDC bus is chosen at 540V. This HVDC bus voltage allows increasing the power level of the mission profile (the maximum consumption of the loads is set to $27 \mathrm{~kW}$ at the beginning of the mission profile). The exact configuration of the test bench is presented in Fig. 11. This one is slightly different with respect to the experimental test with the $28 \mathrm{~V} \mathrm{Li}$ ion battery (a power supply is connected at the HVDC bus and emulates the RAT and the main generator is not used). The emergency mode is immediately activated.

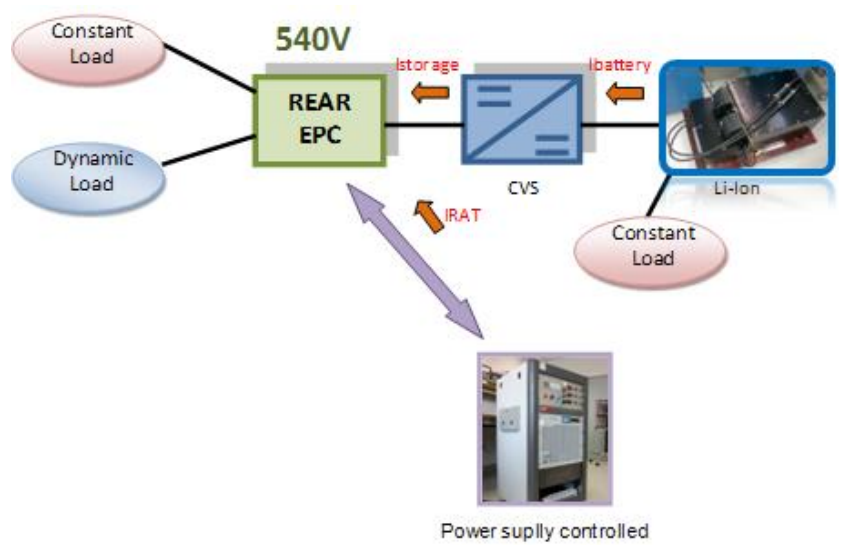

Fig. 11: Test bench configuration with the 216V Li-Ion accumulator

In Fig.12-13, some experimental results are presented with the system being configured as follows:

- Lithium ion battery at nominal voltage $216 \mathrm{~V}$, capacity : 7Ah.

- The cut off frequency of the Low Pass Filter is set at $10 \mathrm{mHz}$.

- The dynamic of the RAT has been implemented in the control of the programmable power supply. During the hybridization, the RAT provides the average power consumption of the loads set to $8 \mathrm{~kW}$.

- The duration of the whole emergency mission is set to 34 minutes.

- The experimental emergency power load profile, with the same scales presented on the Fig.4, has been used. 

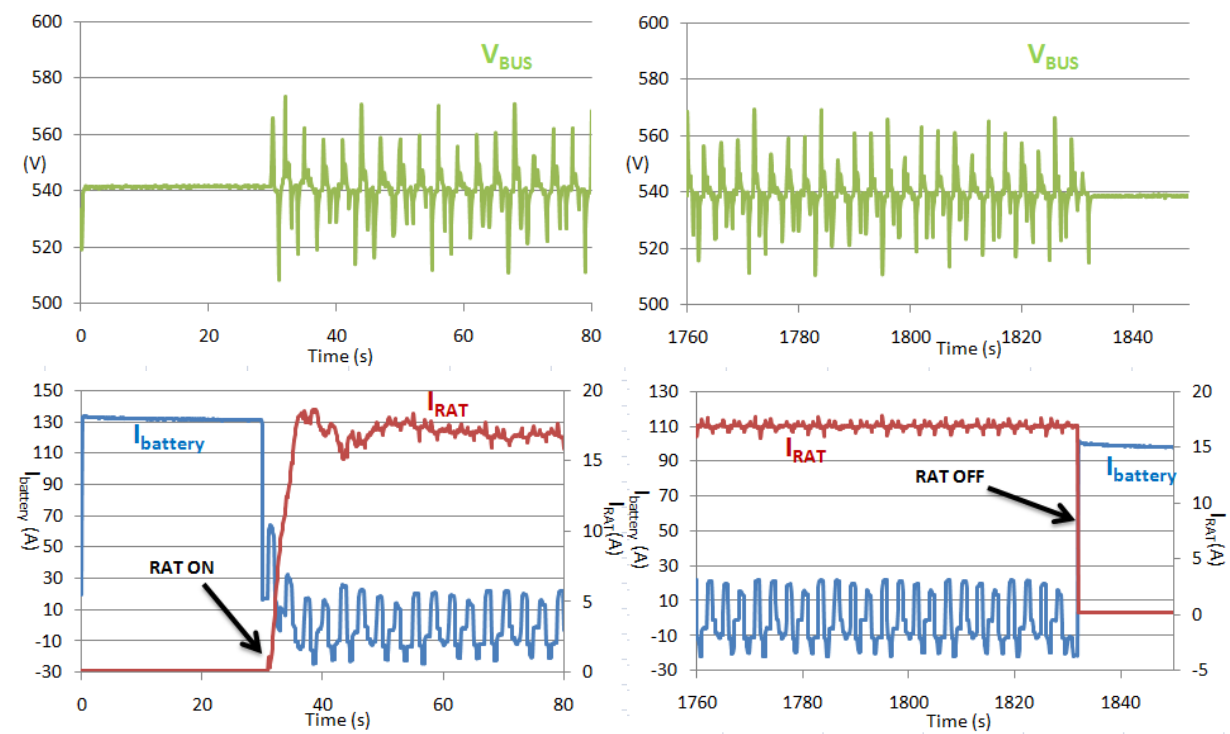

Fig. 12: Experimental results with a 216V Li-Ion accumulator (RAT in current mode)

During the first 30 s ("RAT deployment" phase), the current of the battery is equal to $130 \mathrm{~A}$ ( $27 \mathrm{~kW}$ peak power). When the hybridization phase begins $(\mathrm{t}=30 \mathrm{~s})$, the RAT is used as controlled current source and provides the average power consumption of the load and the battery controls the HVDC bus. As for the experimental results with the $28 \mathrm{~V} \mathrm{Li-Ion} \mathrm{battery,} \mathrm{there} \mathrm{are} \mathrm{high} \mathrm{frequency} \mathrm{components}$ on the HVDC bus voltage due to the limitation of the bandwidth of the DC/DC converter. The voltage ripples on the HVDC bus are approximately $10 \%$ from the voltage bus reference (the HVDC bus capacitor provides the rest of the high frequency components).

Another experimental, with the same test bench, has been carried out with the RAT in voltage mode. Hence, in this configuration, the storage bank operates in a current source and provides the high frequencies components of the load current. As the bandwidth of the battery DC/DC converter is always limited, the RAT (whose converter bandwidth is higher in our experimental bench) provides the remaining high frequencies. The experimental results are shown in Fig. 13. The voltage ripples on the HVDC bus have been strongly reduced compared to the dual configuration.
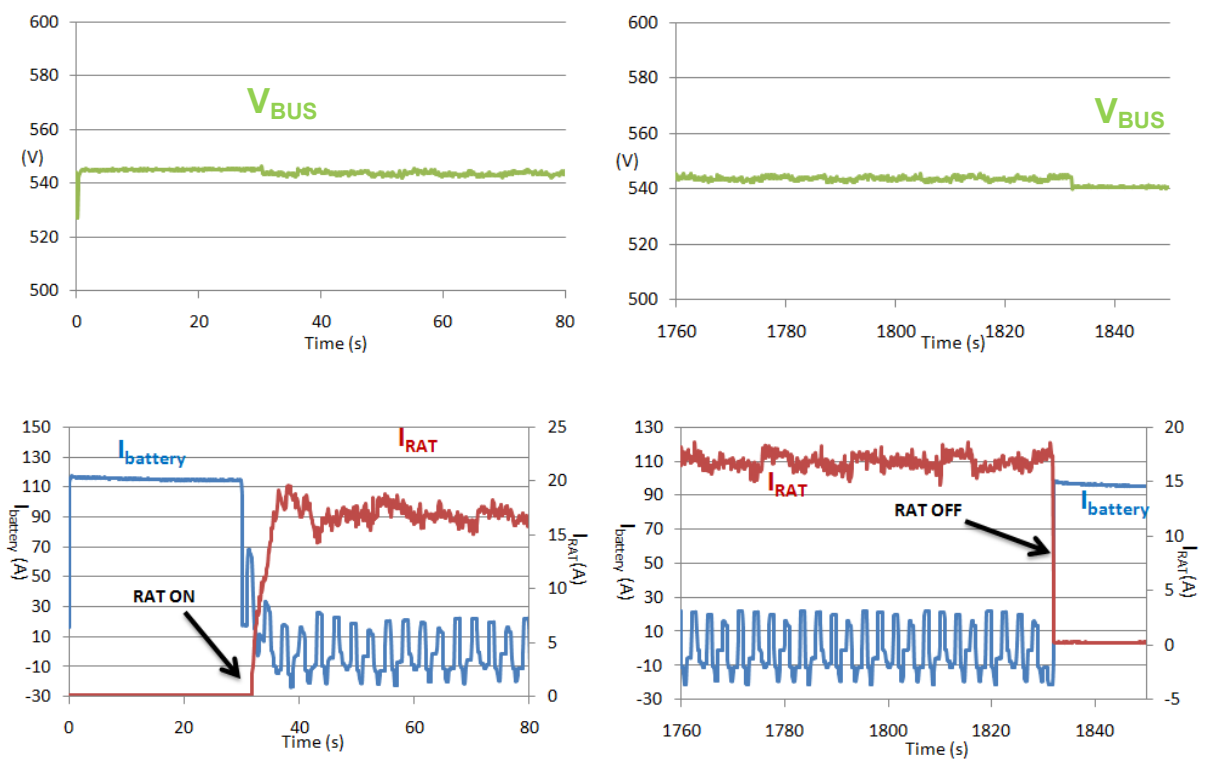

Fig. 13: Experimental results with a $216 \mathrm{~V} \mathrm{Li-Ion} \mathrm{accumulator} \mathrm{(RAT} \mathrm{in} \mathrm{voltage} \mathrm{mode)}$ 


\section{Conclusion}

In this paper, hybridization strategies have been tested on an experimental test bench that interfaces an emulator of the RAT device and lithium ion batteries with two different voltages (28V or 216V) interfaced with a DC/DC bidirectional converter. The converter structure allows interfacing a HVDC bus with medium or low storage voltages. The main generator (RAT sub system) and the load are connected to a HVDC bus, they physically emulate actual dynamics of the aircraft emergency electrical network. These experimental results confirm the ability of such a hybrid structure to efficiently operate with strongly intermittent loads with two hybridization strategies. Another important conclusion of these tests is that the MVDC battery has been optimized in terms of mass and its sizing fulfills the requirements, especially the emergency mission profile.

\section{References}

[1] ACARE, Advisory Council for Aeronautics Research in Europe, Aeronautics and air transport, ACARE success stories, issue march, 2011. Available from: URL : http://www.acare4europe.org/docs/ACARE_Success_Stories_Final.pdf

[2] X. Roboam, New trends and challenges of electrical networks embedded in more electrical aircraft, ISIE, IEEE International Symposium on, Gdansk, 2011, pp. 26-31

[3] J.A. Rosero, J.A. Ortega, E. Aldabas, L. Romeral, Moving towards a more electric aircraft, IEEE Aerospace and Electronic System Magazine, Vol. 22, Issue 3, 2007, pp. 3-9

[4] T. Wu, S. V. Bozhko, G. M. Asher, D. W. P. Thomas, Accelerated functional modeling of aircraft electrical power systems including fault scenarios, IECON, 35th Annual Conference of IEEE, 2009, pp. 2537 - 2544

[5] I. Christou, A. Nelms, I. Cotton, M. Husband, Choice of optimal voltage for more electric aircraft wiring systems, IET Electrical Systems in Transportation, Vol. 1, Issue 1, 2011, pp. 24-30

[6] D. Izquierdo, R. Azcona, F. J. López del Cerro, C. Fernández, B. Delicado, Electrical Power Distribution System (HV270DC) for Application in More Electric Aircraft, APEC, Twenty Fifth Annual IEEE, 2010, pp. 1300-1305

[7] X. Roboam, O. Langlois, H. Piquet, B. Morin, C. Turpin, Hybrid power generation system for aircraft electrical emergency network, IET Trans on Electrical Systems in Transportation, ISSN 2042-9738, Vol. 1, Issue 4, 2011, pp. 148-155

[8] R. Rigo-Mariani, F. Lacressonnière, G. Fontes, X. Roboam, Design of a medium voltage power converterstorage devices embedded in a hybrid emergency network for more electrical aircraft, Mathematics and Computers in Simulation, Vol. 91, May 2013, pp. 72-90 